\title{
Design of Feedback Variable Rate Spraying System Based on ARM
}

\author{
Bing Ji, Bo Zhao*, Yashuo Li, Yanwei Yuan and Xin Dong \\ Chinese Academy of Agricultural Mechanization Sciences, No.1 North Beach, Chaoyang District, Beijing, China 100083 \\ ${ }^{*}$ Corresponding author
}

\begin{abstract}
In order to realize variable rate spraying and ensure the spraying effect, a set of feedback variable spraying control system based on ARM was designed. The system takes the vehicular ARM controller as the core and adopts Linux operating system to obtain the information such as vehicle speed, liquid flow rate and pressure at the nozzle collected by the CAN bus. The system can online process the data and send the function code to the drive circuit, according to the input user's needs, to achieve realization of electric ball valve DC motor speed control under pulse width modulation. And then the current spraying quantity is changed, and ultimately based on the speed of the vehicle. The simulation test and actual vehicle test were carried out. The test results showed that the speed of the vehicle was 4 $10 \mathrm{~km} / \mathrm{h}$ and the control error of this system variable was less than $5 \%$, which satisfied the requirement of variable spraying operation.
\end{abstract}

Keywords—variable spraying; control system; ARM; CAN bus; precision agriculture

\section{INTRODUCTION}

Pesticide is an important production material in agricultural activities. However, excessive input easily leads to environmental pollution and waste of resources. In 2015, the use of pesticides in China was 1.783 million tons, and the pesticide utilization rate in the field was $36.6 \%$ [1], less than the average of $50 \%$ in developed countries [2-3]. Therefore, the urgent need of pesticide use shifted from extensive input to timely, moderate and on-demand positioning input [4].

Variable spraying technology stems from the idea of precision agriculture. This is a kind of technology in which agricultural machinery uses farmland information, combined with its current speed and location to adjust automatically the rate of pesticide input [5]. The traditional spray-based pressure control technology achieves variable spraying by adjusting the system pressure. A large number of experiments show that the droplet diameter changes with pressure is very significant, so the flow control of the method will lose the spray performance [5-15]. Pulse Width Modulation is a variable rate spray technology that solenoid valve is installed at the entrance of the sprinkler, and the intermittent opening and closing of electromagnetic valve is controlled by changing the duty cycle of input signal, so as to achieve variable spray [16-20]. However, high-frequency response and reliability of the solenoid valve are required [15]. Variable rate spraying of online mixing pesticide is a technique to timely change the concentration of a chemical on demand in order to realize the variable spray. Because this method changes the ratio of water and pesticide, it has little influence on the system pressure and flow rate [21-24]. However, due to the small liquid flow rate of the liquid medicine, this control method requires high precision, and there is a certain system delay [18].

\section{WORKING PRINCIPLE OF VARIABLE RATE SPRAYING SYSTEM}

The amount of pesticide applied per hectare during the spraying process is $\mathrm{R}(\mathrm{L} / \mathrm{ha})$ :

$$
R=60000 \int Q / D v
$$

Where: Q-nozzle instantaneous flow, L / min; D- effective spray width, $\mathrm{m}$; v-carrier speed, $\mathrm{m} / \mathrm{s}$.

In practice, $R$ has an expectation based on experience or prescription map. In a certain operation of the spray machine, the effective spray width is a certain value. Then, the nozzle instantaneous flow $Q$ is proportional to the instantaneous speed $v$ of the vehicle. Therefore, in order to ensure that $\mathrm{R}$ reaches the expected value, it is necessary to ensure that $Q$ and $v$ have a fixed and proportional relationship at each moment.

The feedback variable spraying system designed in this paper uses the velocity value $\mathrm{v}$ of the vehicle collected by the sensor, to calculate the target flow rate $Q_{T}$ according to (1), and to obtain the current flow rate $Q_{M}$ through the flow sensor. $Q_{T}$ minus $Q_{M}$ is equal to the feedback value. According to the feedback value, controller takes the appropriate strategy to change the electric ball valve opening, thus changs the liquid flow within the pipeline until $Q_{T}$ is equal to $Q_{M}$, and ultimately achieves variable spraying operations.

In order to ensure a good atomization effect, the crew spray head cone angle has certain requirements. Common nozzle is the fog angle of $110^{\circ}$ double fan nozzle. Spray nozzle spacing, based on the basic requirements, is greater than or equal to $50 \mathrm{~cm}$, while the boom height is generally $50 \mathrm{~cm}$ higher than the crop top. Taken together, the effective spray width $D(\mathrm{~m})$ is:

$$
D=[(m-1) L+2 h \tan \alpha]
$$

Where: m-number of nozzles; L-adjacent two nozzle spacing, m; h-nozzle height from the ground, m; $2 \alpha$-nozzle spray angle. 


\section{SYSTEM HARDWARE COMPONENTS}

\section{A. System Overall Framework}

The overall framework of the variable spraying control system is shown in Figure I. The main structure of the variable spraying control system is a Vehicular ARM controller, a CAN analog acquisition module, a CAN frequency acquisition module, a speed sensor, a flow sensor, a pressure sensor and an electrically adjustable ball valve.

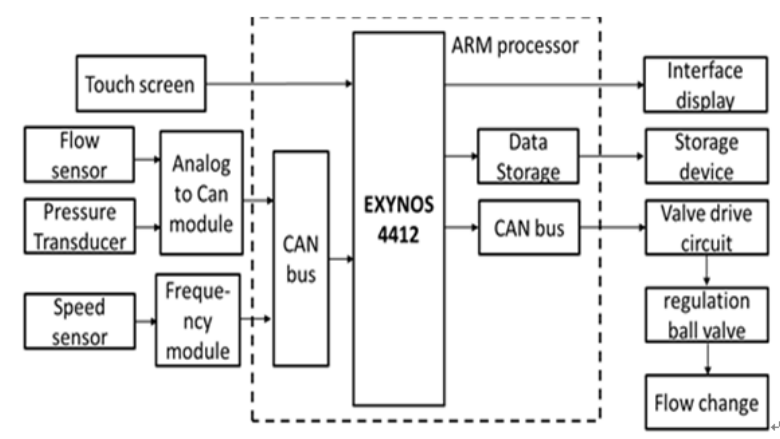

FIGURE I. SYSTEM OVERALL FRAMEWORK DIAGRAM

\section{B. ARM Processor}

Samsung Exynos4412, a Quad-core CORTEX-A9 architecture processor, is selected as the core processor of the system.Ubuntu14.04LTS is adopted as the operating system to collect vehicle speed, pipeline flow, nozzle pressure and other signals, to calculate the theoretical spray amount at current speed, compare feedback signals, output electric ball valve control signal and store real-time data. The peripheral circuit of ARM processor includes Console serial port, standard CAN2.0 bus interface, standard HDMI interface and LCD expansion slot for debugging, communication and display.

\section{Sensors}

\section{1) Speed sensor:}

The speed of the carrier is calculated by measuring the frequency of the output pulse of the Hall sensor. As shown in Figure II, a gear is mounted on the carrier driven wheel shaft. The rotating shaft drives the gear to rotate. When the gear rotates one tooth, the Hall sensor generates a pulse signal, and the signal can be obtained by square shaping after the corresponding square wave pulse.

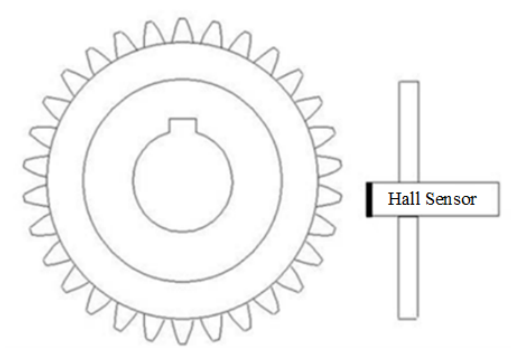

FIGURE II. LOCATION AND METHOD OF SPEED SENSOR INSTALLATION

Vehicle speed $\mathrm{v}(\mathrm{m} / \mathrm{s})$ is:

$$
v=N \pi D / n T
$$

Where: N- Number of pulses collected during acquisition time, D-tire outer diameter, n-gear teeth, and T- acquisition time.

Hall sensor pulse frequency $f x=N / T$. According to (3) it can be obtained:

$$
v=\pi D f_{x} / n
$$

\section{2) Flow sensor:}

Flow collection using electromagnetic flowmeter, accuracy of \pm 0.5 level, the measurement range of 20.00-180.00 L / min, the output signal is isolated $4-20 \mathrm{~mA}$ current signal. The electromagnetic flowmeter is installed on the main pipe according to the installation standard to measure the liquid flow in the system. And flow is one of the main parameters of the variable spray system for feedback regulation.

\section{3) Pressure sensor:}

Nozzle pressure at the collection using the pressure transmitter, the measuring range is $0-1 \mathrm{Mpa}$.Transmitter is installed with tee connection in the general pipeline, in front of the nozzle and after the flow sensor. It is used to measure the pressure value at the nozzle. In the case of a double sector fan and brown nozzle (No.5 nozzle), the atomization effect is better at $0.2-0.5 \mathrm{Mpa}$. Therefore, the spray nozzle pressure, which influences the spray effects, is one of the important parameters to collect in the spray system.

\section{4) Acquisition module:}

Acquisition module is uesd to acquire sensor signal and convert it to CAN signal. The signal is sent to the ARM controller via the CAN bus. There are ICAN-3402 analog acquisition module and ICAN-7404 frequency measurement module. The modules are installed with the appropriate sensor nearby.

\section{5) Electrically adjustable ball valve:}

The electrically adjustable ball valve is consists of an Rtype valve body and a DC-speed regulated motor. The motor drives the valve body spool to change its travel to change the maximum flow rate through the valve body. The percentage flow of the valve is proportional to the percentage of travel. The speed of valve motor is 3RPM. It takes only $6 \mathrm{~s}$ from fully close to fully open.

\section{VARIABLES SPRAY CONTROL METHOD}

As shown in Figure III, it is the block diagram of the system closed-loop control. In the feedback regulation, the measurement accuracy of the feedback and delay has a significant impact on the characteristics of the closed-loop system. According to the working principle of the variable rate spraying system, the feedback value is determined by the vehicle speed $\mathrm{v}$ and the current flow $\mathrm{Q}_{\mathrm{M}}$. Appropriate electromagnetic flowmeter is selected to improve the accuracy of flow measurement and reduce response time during current flow measurement. As the measurement delay of vehicle speed 
is negligible, the accuracy of speed measurement is very significant. Frequency measurement method is proposed to replace the commonly used counting method to improve speed accuracy. The system delay mainly comes from regulation of the adjustable ball valve. Therefore, the pulse width modulation strategy is chosen by the controller to reduce the settling time caused by the valve delay.

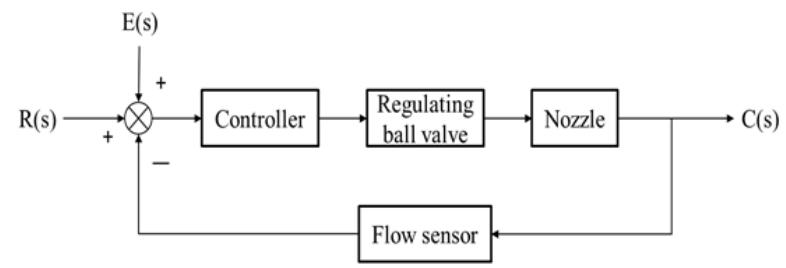

FIGURE III. PRINCIPLE BLOCK DIAGRAM OF CLOSED-LOOP CONTROL SYSTEM

Comparison of speed measurement, frequency method and counting method: (4) is the theoretical formula for calculating the speed using frequency measurement method. Frequency measurement module can measure $f x$, the frequency of the pulse signal output by the sensor. The principle of frequency measurement is shown in Figure IV.

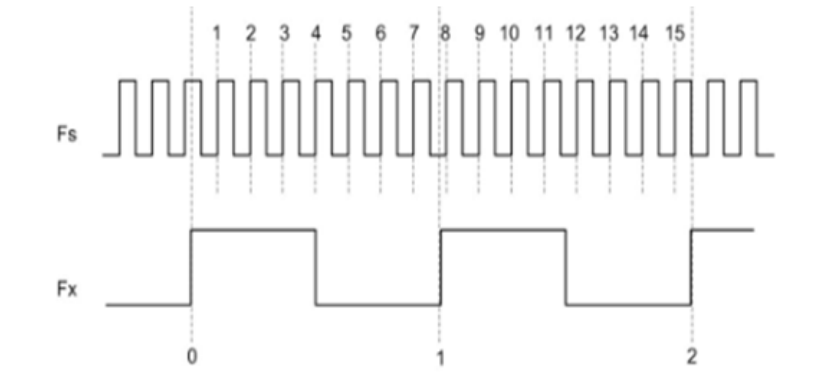

FIGURE IV. PRINCIPLE OF EQUAL PRECISION MEASUREMENT OF FREQUENCY

fs is the internal standard fundamental frequency, $f x$ is the measured signal frequency. When detecting the rising edge of the measured wsignal, the module starts to count the measured signal and the baseband signal at the same time. The count value increases at the rising edge. When the measured signal reaches the preset number of frequency measurement, signal and baseband signal count, assuming the number of counts $N x$ and Ns, respectively. The following equation holds:

$$
f_{x} / N_{x}=f_{s} / N_{s}
$$

The frequency of the signal is obtained under test: $f x=f_{S} N x / N s$.

During the operation of the vehicle, the instantaneous speed is always changing. So that the acquisition of instantaneous speed do not have any practical meaning. Therefore, the average frequency obtained after measuring a certain number of pulse signals is used to calculate the average speed.
Comparison is made between counting method and frequency measurement method according to (3) and (4):

According to (3), one can measure the average speed within the acquisition time $\mathrm{T}$, but when a tooth top passes through the Hall sensor and the next tooth top does not run to the sensing area, there is a pulse error. Then the theoretical relative error of the average speed is $1 / N$.

In one measurement using frequency measurement method, the count of the start-stop time is measured by the rising edge of the signal triggered. Therefore, the measured signal number of count $N x$ has no error, while the basic frequency signal count Ns only differs by a pulse. Thus measurement accuracy has nothing to do with the frequency of the measured signal. The speed measured by the frequency measurement method is of $1 /\left(N_{s}+1\right)$ of relative error.

The relative error of frequency measurement method is related to the measurement system itself, but has nothing to do with the measured signal. And Ns is much larger than $N$ in the same time, so the speed measurement by frequency-measuring method is better than the method of counting.

1) PWM mode to reduce settling time of closed-loop Control:

In the feedback adjustment process, when the current flow rate is close to the target flow rate, pulse-width modulation strategy is selected by the controller to reduce the speed of the ball valve motor and the overshoot caused by the delay, resulting in reduced settling time, which is equivalent to reducing the delay characteristics of the ball valve.

PWM mode motor control method is:

The current feedback value is calculated by the ARM according to information collected by sensors. Therefore, judgment about choosing corresponding function code to send is made. The function code is used to control the polarity and size of the input voltage of the ball valve and the on-off, to change the DC motor state and the opening of the ball valve.

Function code FC can be expressed as:

$$
F C=\left\{\begin{array}{cc}
1, & C_{1}<\left|Q_{M}-Q_{T}\right| /\left|Q_{T}\right| \\
0, & C_{0}<\left|Q_{M}-Q_{T}\right| /\left|Q_{T}\right|<C_{1} \\
-1, & 0<\left|Q_{M}-Q_{T}\right| /\left|Q_{T}\right|<C_{0}
\end{array}\right.
$$

When $F C=1$, working in full speed mode, the ball valve motor rotates at full speed;

When $F C=0$, working in PWM mode, ball valve motor speed reduces, real-time calculation of duty cycle program runs in ARM;

When $F C=-1$, the control valve does not move, no change of the flux.

$C_{0}$ is related to the maximum allowable error of the system, equal to $5 \%$. $C_{1}$ was obtained by experiment as $15 \%$. The tests and analysis, is presented at Section 5 . 
The calculation of duty cycle during Pulse Width Modulation is designed as following.

When $F C=0$, the system adopts the PWM mode to adjust the motor speed. The motor speed decrease curve is similar to the following arc tangent function curve. Duty cycle is calculated through the curve discretization. The reason for selecting this speed curve is that the speed reduced rapidly in this way, and the acceleration in the first and last stages of the deceleration process is small and the acceleration in the middle is large. This will reduce the speed faster, while reduce the settling time.

Curve equation of the chosen arc tangent function is:

$$
f(x)=\frac{1}{2.94}\left(\tan ^{-1}(10-x)+\tan ^{-1} 10\right)
$$

Where $f(0)=1.0008, f(20)=0$.

In the speed-time curve, the area enclosed by the curve and the abscissa represents the distance, noticing that:

$$
\int_{0}^{15} v(t) d t / \int_{0}^{20} v(t) d t=0.9935
$$

Therefore, the curve within the range of [0-15] may be approximately replaced by the original curve to further reduce the additional settling time caused by the deceleration.

\section{DESIGN OF SYSTEM SOFTWARE}

\section{A. Design of Communication Protocol}

Vehicular ARM controller and the CAN acquisition module, the core components such as sensors are connected by CAN bus network.

CAN bus physical layer and data link layer is complied with CAN2.0B standard frame protocol (CAN2.0A compatible). Designed function codes are defined in the 11-bit identifier in the message for the application layer. ARM equipped with Ubuntu operating system adopted in ARM use Socket CAN to achieve CAN bus communication. CAN Socket Driver, is one of the character-based devices of Linux to achieve CAN communication protocol.

Application layer main function codes are designed as shown in Table I:

\begin{tabular}{|c|c|c|c|c|}
\hline $\begin{array}{c}\text { Acquisitio } \\
\text { n begins / } \\
\text { ends }\end{array}$ & $\begin{array}{c}\text { Acquisition } \\
\text { channel }\end{array}$ & $\begin{array}{l}\text { Forward/ } \\
\text { Reverse }\end{array}$ & valve speed & $\begin{array}{c}\text { Frequency } \\
\text { interval } \\
\text { setting }\end{array}$ \\
\hline $\begin{array}{l}000+0101 \\
\quad / 0801\end{array}$ & $\begin{array}{c}\text { 381: } \\
\text { pressure, } \\
\text { flow } \\
\text { 382: speed }\end{array}$ & $\begin{array}{c}201+01 \\
\quad / 02\end{array}$ & $0000 \sim \mathrm{cc} 0 \mathrm{c}$ & $\begin{array}{c}202+18050 \\
000 \sim 18050 \\
3 \mathrm{E} 8\end{array}$ \\
\hline
\end{tabular}

TABLE I. APPLICATION LAYER FUNCTION CODE

\section{B. Program Flow Block Diagram}

As shown in Figure V, there are data flow block diagram and control loop block diagram. The programming language is $C$ language. An ARM platform executable file is generated through a cross-compiling tool to realize data processing and closed-loop control.

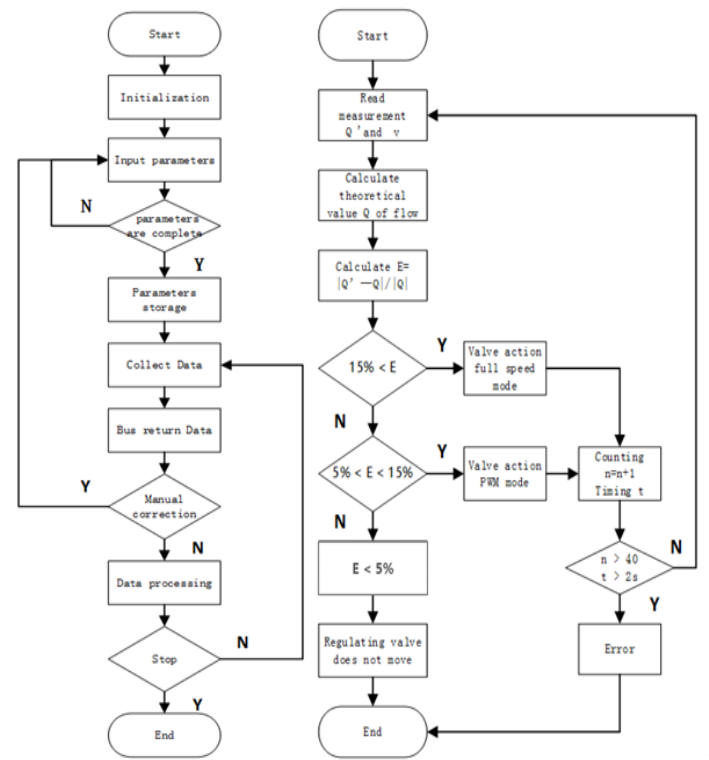

FIGURE V. DATA FLOW BLOCK DIAGRAM AND CONTROL LOOP BLOCK DIAGRAM

\section{Design of Interface}

Figure VI shows the main interface of the software, showing the main spray nozzle pressure, vehicle speed, flow information, flow - time curve, the height of the boom from the ground, the number of nozzles, spacing, and work status and time. Function keys include: manual correction mode increase and decrease key "+", "-", automatic, manual mode, start and stop keys. Interface can easily monitor the spray machine operating conditions, under special circumstances can be manually corrected.

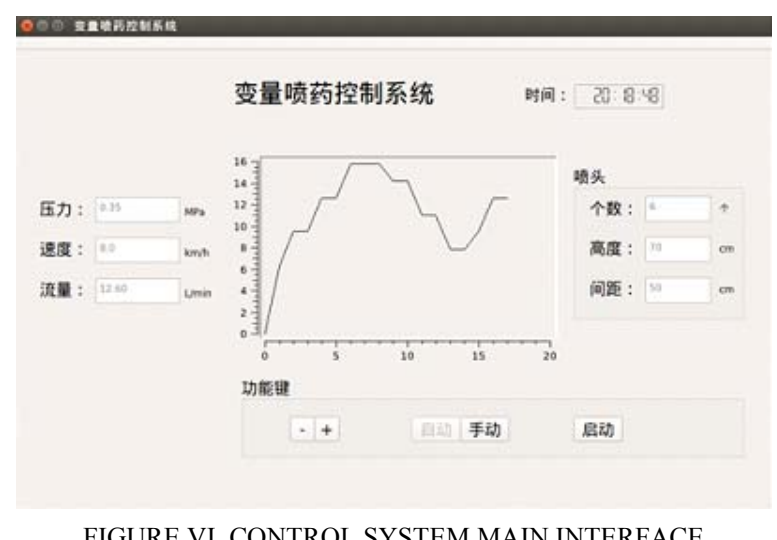

FIGURE VI. CONTROL SYSTEM MAIN INTERFACE 


\section{TEST AND ANALYSIS}

\section{A. $C_{1}$ Value Determination Test}

Parameter $C_{l}$ is designed to reduce the system settling time. $C_{1}$ is the demarcation of full-speed mode and PWM mode of valve motor speed controlling. A test platform is set up and a simulation test designed to verify whether $C_{1}$ is valid and choose the optimal $C_{l}$ value.

With different $C_{1}$ values and different vehicle speeds as dependent variables, variable-rate spraying experiments were conducted to obtain multiple sets of system settling time. The value of $C_{1}$ as the $\mathrm{X}$-axis, the speed of the carrier as the $\mathrm{Y}$-axis, and the system settling time is the $\mathrm{Z}$-axis, resulting in the curves of Figure VII and Figure VIII. By definition $C_{1}>5 \%$, however, one set of tests take $C_{1}=C_{0}=5 \%$. Which means FC constant is not equal to 0 ; the motor does not work in the PWM speed control mode, in other words, I.e. $C_{l}$ invalid parameter. This group of tests compared with several other groups of tests to verify that the parameter settings can effectively reduce the settling time.

As shown in Figure VIII, the $\mathrm{X}$-axis is the $C_{1}$ value, taking $5 \% \sim 25 \%$. Y-axis is vehicle speed, taking $4,5,6,7,8,9,10$ $\mathrm{km} / \mathrm{h}$, which are common spray machine operating speed. The $\mathrm{Z}$-axis is the corresponding settling time measured by the test ( $5 \%$ overshoot).

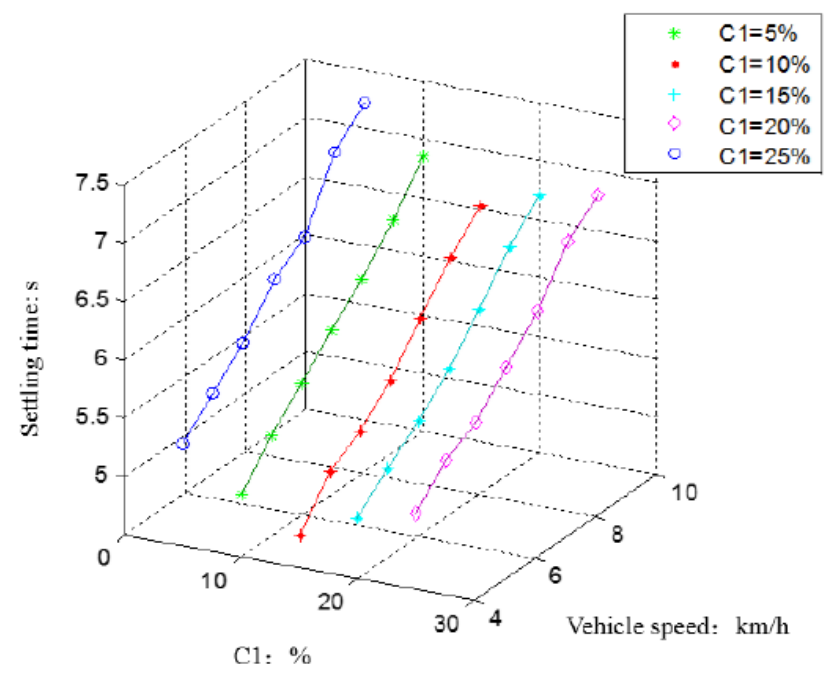

FIGURE VII. C1-SPEED-SETTLING TIME CURVE

Figure VIII is a two-dimensional curve of Figure VII in the $\mathrm{Y}-\mathrm{Z}$ axis view for ease of analysis. As shown in Figure VIII, when $C_{1}>5 \%$, the settling time is significantly reduced than when $C_{l}=5 \%$, so PWM speed regulation can effectively reduce the settling time, in line with expectations.

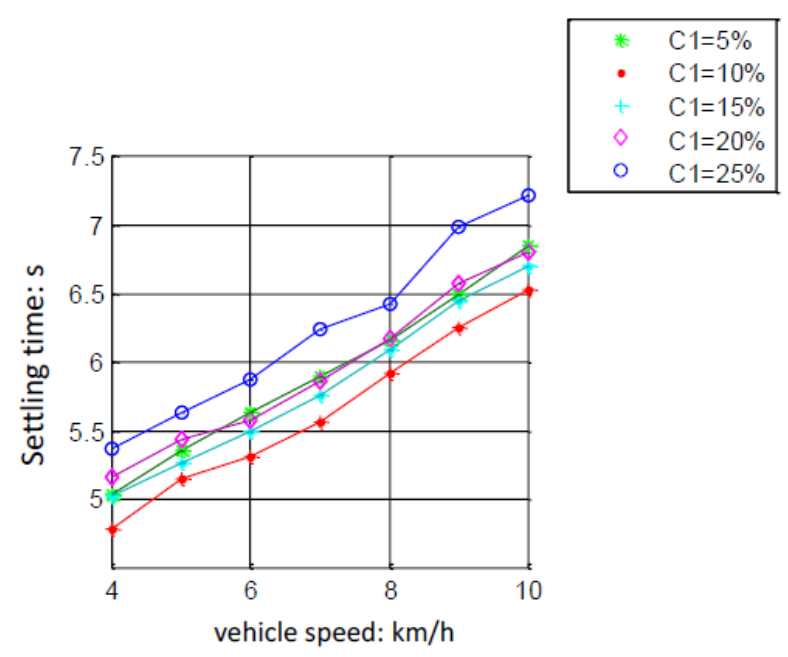

FIGURE VIII. SPEED-SETTLING TIME CURVE

When $C_{1}=15 \%$, the settling time is smaller than other $C_{1}$ values. When $5 \%<C_{1}<15 \%$, the settling time decreases with the increase of $\mathrm{C}_{1}$ at different vehicle speed, and the reduction of settling time caused by PWM mode is the main factor. When $C_{1}>15 \%$, the settling time increases with the increase of $C_{1}$, because when the value of $C_{1}$ is too large, the deceleration process starts too early. The increase of the time caused by the speed decrease is greater than time reduction caused by the controller strategy. The final performance for the settling time increases. Taken together, the optimal value of $C_{l}$ is chosen as $15 \%$.

\section{B. Real Vehicle Tests}

The variable spraying control system which be installed to 3WQ-3000 traction bar spray machine was selected in the real vehicle tests. Field trials conducted in Shanxi Province from December 6, 2017 to December 8, 2017, as seen in Figure IX.

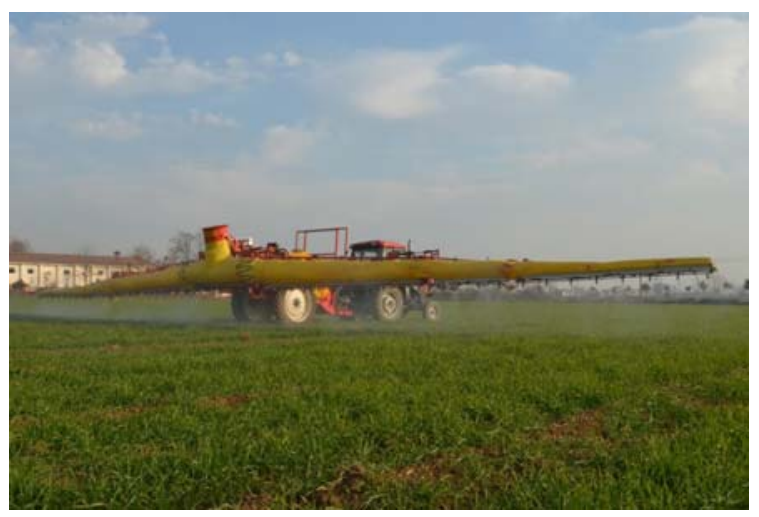

FIGURE IX. REAL VEHICLE TESTS SCENE

\section{1) System speed detection precision test:}

As shown in Figure $\mathrm{X}$, the blue curve is a curve measured by Omron absolute encoder which shows the speed curve of the spraying machine during the time of December 6, 2017 17:22:01 5000 milliseconds to 44 seconds 3000 milliseconds. The encoder's resolution is $1024 \mathrm{P} / \mathrm{R}$, so that the blue curve can be used as a standard speed curve. The green curve is the 
speed curve measured by this system using the counting method, and the red curve is the speed curve measured by the system using the frequency measurement method.

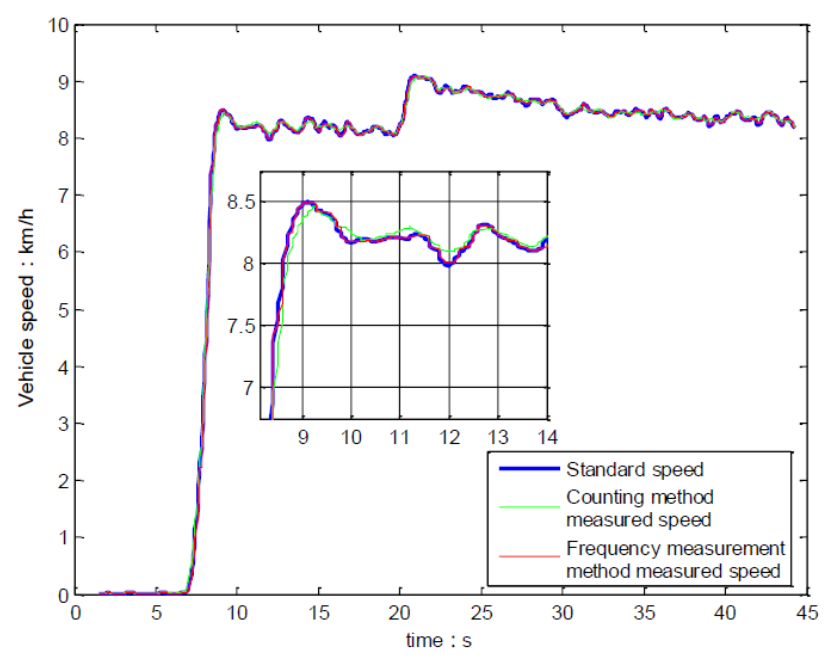

FIGURE X. RESULTS OF SYSTEM SPEED DETECTION ACCURACY VERIFICATION TEST

As shown in Figure $\mathrm{X}$, the blue curve is a curve measured by Omron absolute encoder which shows the speed curve of the spraying machine during the time of December 6, 2017 17:22:01 5000 milliseconds to 44 seconds 3000 milliseconds. The encoder's resolution is $1024 \mathrm{P} / \mathrm{R}$, so that the blue curve can be used as a standard speed curve. The green curve is the speed curve measured by this system using the counting method, and the red curve is the speed curve measured by the system using the frequency measurement method.

Each curve includes 1032 points. Red and green curves were compared with the standard curve. The following results were obtained:

The average error of the red curve and the standard curve is $0.86 \%$, the mean square deviation is $\sigma_{r}=0.0307$;

The average error of green curve and standard curve is $3.35 \%$, mean square deviation is $\sigma_{g}=0.0549$;

Therefore, the red curve is more in line with the standard speed curve and the frequency measurement method is more accurate than counting method.

\section{2) Variable spraying operation test at different speed:}

The desired amount of spray $\mathrm{R}$ is set $300 \mathrm{~L} / \mathrm{ha}$. The number of spray nozzle $\mathrm{m}$ is 51 , and the spacing is $50 \mathrm{~cm}$. ground clearance equals to $80 \mathrm{~cm}$. Spraying machine were continuously working at different speeds for $1 \mathrm{~min}$ each(different speed test independent of each other, and each test started in speed of zero). The volume of water sprayed was as the spray volume. According to the operating data stored in ARM, Table II is obtained.
TABLE II. VARIABLE SPRAYING OPERATION TESTS AT DIFFERENT SPEED

\begin{tabular}{|c|c|c|c|c|}
\hline \multirow{2}{*}{$\begin{array}{c}\text { Variable } \\
\text { (Speed: } \\
\text { km/h) }\end{array}$} & \multicolumn{4}{|c|}{ Measurement and Calculation Results } \\
\cline { 2 - 5 } & $\begin{array}{c}\text { Theoretic } \\
\text { al spray } \\
\text { amount: } \\
\text { L/ha }\end{array}$ & $\begin{array}{c}\text { Actual } \\
\text { spray } \\
\text { amount: } \\
\text { L/ha }\end{array}$ & $\begin{array}{c}\text { Percentag } \\
\text { e error: \% }\end{array}$ & $\begin{array}{c}\text { Settling } \\
\text { time: } \boldsymbol{s}\end{array}$ \\
\hline 4 & 51.00 & 52.53 & 3.0 & 0.73 \\
\hline 5 & 63.75 & 65.28 & 2.4 & 0.67 \\
\hline 6 & 76.50 & 77.01 & 0.7 & 0.71 \\
\hline 7 & 89.25 & 86.70 & 2.9 & 0.69 \\
\hline 8 & 102.00 & 100.47 & 1.5 & 0.67 \\
\hline 9 & 114.24 & 109.14 & 4.5 & 0.63 \\
\hline 10 & 126.99 & 126.48 & 0.4 & 0.69 \\
\hline
\end{tabular}

As can be seen from Table II, when the vehicle speed is 4 $\sim 6 \mathrm{~km} / \mathrm{h}$, the actual spraying amount is slightly larger than the theoretical spraying amount. When the vehicle speed is $7 \sim$ $10 \mathrm{~km} / \mathrm{h}$, the actual spraying amount is slightly less than the theoretical spraying amount. Repeated tests and observations, the following analysis were drawn: When the speed is more than $8 \mathrm{~km} / \mathrm{h}$, the pipeline pressure is relatively large. The backflow valve, which plays a role to stable pressure and limit the maximum pressure, will produce a flow back, resulting in reduction of pressure at the nozzle, making the actual amount of spray slightly lower than the theoretical value. When the speed is slow, the spray amount is small, while backflow valve do not work. Pressure provided by the pump is concentrated in the nozzle, making the actual spray slightly higher than the theoretical value.

However, at different speeds, the system does not exceed $5 \%$ of the percentage of spraying error during spraying.

\section{CONCLUSION AND PROSPECT}

A. A Variable Rate Spraying Control System Based on Canbus is Designed and Set Up with ARM Processor as its Core. Control System Interface is Designed to Achieve Conditions Monitoring, Automatic Variable Control and Manual Correction, and Job Data Storage Functions;

B. Speed Measurement Error is Less Than 2\%, the System can Accurately Measure the Carrier Speed, in Line with the Application Requirements;

C. According to the Variable Spraying Operation Test, it is Concluded that: The Control Error of the Variable Spraying System is less than 5\%. The Settling Time is Less Than 0.75s. And the Variable Spraying Operation Requirement is Met.

D. Positioning Technology such as GPS Positioning Technology can be Applied to the System. Therefore, the System can Change the Expected Spray Quantity R in Real Time According to the Location and the Prescription Map Information, so as to Realize the Variable Spraying Operation According to the Prescription Map. Also, Longrange Communication Means such as DTU Module can be Added to the System to Realize the Remote Interaction of the Data and Remote Control of Variable Spraying. 


\section{ACKNOWLEDGMENT}

This paper is supported by the national key research and development program of China (No. 2017YFD700500).

\section{REFERENCES}

[1] S Jin, F Zhou, "Zero Growth of Chemical Fertilizer and Pesticide Use: China's Objectives, Progress and Challenges," China Development Observation, 2017(13):35-39. (in Chinese)

[2] Fu Z, Qi L, Wang J, "Developmental tendency and strategies of precision pesticide application techniques," Transactions of the Chinese Society for Agricultural Machinery, 2007. (in Chinese)

[3] Zhang F, Hong T, Wang J, et al, "Development of Modern Pesticide Spray Technique and Equipment," Journal of Agricultural Mechanization Research, 2011. (in Chinese)

[4] Qiu B, Yan R, Jing M, et al, "Research Progress Analysis of Variable Rate Sprayer Technology," Nongye Jixie Xuebao/transactions of the Chinese Society of Agricultural Machinery, vol 46, pp. 59-72, 2015 (in Chinese)

[5] Shi W, Wang X, Wang X Z, et al, "Study on Variable Rate Spraying Technology Based on Pulse Width Modulation and Volume Control," Journal of Agricultural Mechanization Research, 2007. (in Chinese)

[6] Xuan Z, Yang F, Liu L," Design of controlling system for variable rate spraying based on microcontroller," Journal of Northeast Agricultural University, 2009. (in Chinese)

[7] Zhai $\mathrm{C} \mathrm{Y}$, Zhu R X, Sui S T, et al, "Design and experiment of control system of variable pesticide application machine hauled by tractor," Transactions of the Chinese Society of Agricultural Engineering, vol 25,pp. 105-109, 2009. (in Chinese)

[8] Huang S, Zhu R, Wang Y, et al, "Design and Algorithm of Constant Pressure and Variable Flow Control System of Variable Pesticide Application Machine," Journal of Agricultural Mechanization Research, 2011. (in Chinese)

[9] Liang X, Chen Z, Zhang X, et al, "The On-line Monitoring System of Combine Harvester Base on CAN-BUS," Journal of Agricultural Mechanization Research, 2013. (in Chinese)

[10] Yin D,"Design of cotton variable target weed spraying system based on ARM9[D]. Jiangsu University, 2011. (in Chinese)

[11] Shao L, "Study on a Pesticide System Spraying with Changeable Quantity Based on Fuzzy Control," Transactions of the Chinese Society of Agricultural Machinery, vol. 36, pp. 110-112, 2005. (in Chinese)

[12] $\mathrm{Na} \mathrm{G}, \mathrm{Hu} \mathrm{J}$, "Design and experiment of variable rate spaying system on Smith-Fuzzy PID control," Transactions of the Chinese Society of Agricultural Engineering, vol. 30, pp. 56-64, 2014. (in Chinese)

[13] Chen S, Yin D, Wei X, et al, "Design and simulation of variable weed spraying controller based on adaptive neural fuzzy inference system," Journal of Drainage \& Irrigation Machinery Engineering, vol. 29 no.3, pp. 272-276, 2011. (in Chinese)

[14] Wang L X, Zhang S H, Ma C L, et al, "Design of variable spraying system based on ARM,'Transactions of the Chinese Society of Agricultural Engineering, vol. 26,no.4, pp. 113-118, 2010. (in Chinese)

[15] Shi Y, Qi L, Fu Z, et al, "Model development and simulation of variable rate of pressure spray," Transactions of the Chinese Society of Agricultural Engineering, vol. 20, no. 5, pp. 118-121, 2004. (in Chinese)

[16] Wei X, Jiang S, Sun H, et al, "Design and test of variable rate application controller of intermittent spray based on PWM," Transactions of the Chinese Society for Agricultural Machinery, vol. 43, no. 11, pp. 87-93+129, 2012. (in Chinese)

[17] Wang H A, Chen S B, "The Design and Experimental Research of Variable Spraying System Based on PWM," Journal of Agricultural Mechanization Research, 2012. (in Chinese)

[18] Deng W, Ding W, He X, "Droplet velocity and energy characteristics of continuously variable spray based on pulse width modulation," Transactions of the Chinese Society of Agricultural Engineering, vol. 25pp. 66-69, 2009. (in Chinese)
[19] Shen C, Qiu B, Chen S, et al, "The Variable Applying Pesticide Device Based on the Electric Proportional Valve," Journal of Agricultural Mechanization Research,vol. 32no.2, pp. 91-93, 2010. (in Chinese)

[20] Wei X, Jiang S, Zhang J, et al, "Application rate control characteristics of blended pulse variable rate application system," Transactions of the Chinese Society for Agricultural Machinery, vol.44no.2, pp. 87-92+86, 2013. (in Chinese)

[21] Yan D, Zhang W, Wang X, et al, "The Design of Pesticide Variable Injection Control System Based on PWM," Journal of Agricultural Mechanization Research, 2011. (in Chinese)

[22] Zhang W, Liu Z, "Experiment on variable rate spray with real-time mixing pesticide of 3 WY-A3 sprayer," Transactions of the Chinese Society of Agricultural Engineering, vol. 27, no. 11, pp. 130-133, 2011. (in Chinese)

[23] Cai X, Martin W, Malte D, et al, "Direct nozzle injection sprayer based on electromagnetic-force valve," Transactions of the Chinese Society for Agricultural Machinery, vol. 44, no. 6, pp. 69-72+200, 2013. (in Chinese)

[24] Liu Z Z, Xu H H, Hong T S, et al, "Key technology of variable-rate spraying system of online mixing pesticide," Transactions of the Chinese Society for Agricultural Machinery, 2009. (in Chinese) 